\title{
Editorial
}

\section{John Hilsdon}

University of Plymouth, UK

It has taken almost a year to prepare this first edition of the Journal of Learning Development in Higher Education, and so it is with some relief as well as much pleasure that I came finally to write this editorial. There is a great deal to say about how we got to this point, and some of that story is told by contributors to the current issue of the journal, notably Christine Keenan. At the inception of our network in 2003 the term 'Learning Development' was not yet in common use; now it is to be found quite frequently in titles of posts, units and services in many $\mathrm{HE}$ institutions. More importantly, the teaching, research, policy and developmental activities of those who choose to use the phrase have now had such impact on the sector that writing or speaking of Learning Development work, the LD community or profession is no longer novel; nor do I feel obliged to qualify it as 'emergent', as I have done previously.

Though definitions of LD are likely to remain the subject of discussion and debate, as an approach to working with students in universities to improve their learning, the scope and practice of LD has been quite extensively described in conversations posted to the email list LDHEN since 2003. Most notably, it is the commitment to look at the whole HE learning experience from students' perspectives that has marked the development of the field.

It is true, as Chris Rust argues in his opinion piece in this issue, 'a call to unite in a common cause', that there are dangers in concentrating on what divides us from our colleagues in the more traditional educational development roles. Chris suggests that now is a uniquely propitious time to work together, drawing attention to factors where the combined insights and expertise of LD and ED with academics could help us address some of the current issues around the effectiveness of assessment; the need for clarity of purposes for HE in meeting social and economic needs, and in meeting the challenges of demographic changes. His worries are that if we cannot 
unite, the tendency for institutions to go for seemingly cheap 'support' options, especially e-learning 'solutions', will increase. He suggests a new drive to work with academics to develop common understandings and approaches to the $\mathrm{HE}$ experience, which has a strong appeal for us all. Drawing upon notions such as 'threshold concepts' and graduate attributes he calls upon us to work jointly for a 'paradigm shift'; giving centrality to learning but retaining the perspective of disciplinary practice.

There can be no doubt, however, that the emergence of the distinctive LD community is a phenomenon worthy of attention and, as Chris acknowledges, its supportive functions for practitioners are greatly valued. This is manifested, as Christine Keenan describes in her article, in the highly active LDHEN discussions over the last few years; the outputs from six very successful conferences; and the establishment of a Centre for Excellence in Teaching and Learning specialising in LD: 'LearnHigher'. For many in the UK LD community it was a pivotal moment when we achieved success in our bid for funding from the Higher Education Funding Council for England in 2004, to set up LearnHigher. For this reason it is especially important to see aspects of the CETL's work referred to in several articles here. In 'Reaping the Fruits of Collaboration', Kim Shahabudin outlines the some of the uniquely reflective and practice-based learning development research undertaken across the 16 universities in the CETL partnership. There is also a case study by Carol Elston, one of the CETL's developers, which discusses the LearnHigher 'groupwork' learning resource. Alongside this, we have an independent review by Jackie Cawkwell of the 'groupwork' resource, and some comments about the website overall.

Addressing our community by taking a comparative and historical view from a variety of HE contexts, Graham Gibbs draws upon his experience as an educational developer over 30 years to offer a conceptual map for the possible evolution of LD. In outlining the inter-related 'domains' of learning and pointing to the complex implications of highly context-dependent and varied HE experiences, he warns against simplistic generalisations about what learning development should consist of. Reminding us of how ED's focus on developing teaching has shifted from largely individual and 'micro', to more strategic and 'macro' features (towards institutional teaching and learning strategies, for example), he challenges us to consider how our 
LD initiatives may have greatest impact - to learn from and build on ED's "decades of development and institutional integration".

By contrast, in drawing our attention to the importance of the 'emotion work' associated with supporting students, Jan Huyton's paper offers a counter view to those who envisage a complete 'embedding' of LD into subject contexts and undertaken only by subject-specialist academics or members of course teams. She also opposes those who deride such work as part of a 'therapeutic turn' in education which characterises students as essentially needy. Jan poses important questions about tutors' responses to students' emotional issues, and makes a key contribution to the debate which our 2009 LDHEN Symposium will also feature, where Dennis Hayes and Alan Mortiboys offer contrasting interpretations of the role of emotion in learning. We anticipate that the next issue of the JLDHE will follow up on this highly contested debate.

Jan notes evidence that use of the language of support and emotional well-being in institutional practices may actually be a marketing tool seeking to manage student retention and satisfaction with the curriculum and the institution. Where such institutional drives over-ride more genuine and pedagogically inclined approaches problems are likely to arise. She points out that staff also experience the need for support as a consequence of the growing levels of emotion work they are required to undertake, and calls for a wholesale re-examination of this area in relation to pedagogy and to learning relationships.

Richard Bailey's paper on the ways that students interpret and attempt to make use of written feedback relates to Huyton's arguments by pointing to findings that suggest many students feel frustrated and confused by feedback; they find it inconsistent and vague. This is not helped by increasing uniformity in, for example, the use of standardised feedback forms and the lack of opportunities for genuine dialogue about assessed work. Consequently an important - but contested - role for learning developers is as mediators in working with students to demystify assessment and feedback processes. How we negotiate the boundaries of such a role is a question ripe for further examination. 
There are links here to McKinney, Wood and Little's paper, which explores the often hybrid nature of LD type roles by presenting a model of a 'Learning Development and Research Associate' whose work is to support staff and students in the development of collaborative inquiry or 'Inquiry-based Learning' approaches. Focussing on experiences at the University of Sheffield's Centre for Inquiry-based Learning in the Arts and Social Sciences a 'brokering' role is explored. A related set of case studies by Jamie Wood is also included in this issue. Here the need to engage students with the questions and problems of their academic or professional disciplines is emphasised, combined with the importance of 'scaffolding' and supporting them in developing their own inquiry process. Similarly, Annamarie McKie describes the need to help students develop the skills to undertake effective, focused searches. Whilst the pervasiveness of computers and the use of Google might lead to assumptions about young people being 'digital natives', she argues that many students actually spend very little time in evaluating information for relevance, accuracy or authority. Given findings about how students spend their time online, Annamarie suggests a range of flexible and active learning workshops to address these issues.

Helen Bowstead writes of her personal journey from teaching English as a Foreign Language to taking on an LD role in an HE institution, reflecting how issues of language, alienation and academic literacy are relevant in both cases. The extent to which students and staff feel themselves to be 'insiders' or 'outsiders' of the academic community has a great impact on what we can achieve. It is the need to find an authentic voice, the struggle to have it accepted, and then use it to participate that Helen identifies as most vital.

In "Mrs Mop, Mechanic and/or Miracle Worker: metaphors of study support" Celia Bishop, Christine Bowmaker and Terry Finnigan of the University of the Arts, London emphasise that LD practitioners are part of the academy, not separate from it, and that we need to reflect on our relationships within our own community and institution. This fascinating paper reminds us of the power of metaphor in understanding roles and relationships, how we see ourselves and how we are perceived by others. The metaphors we choose help to reveal assumptions about underlying power-relations and the implied theoretical orientations of LD roles. In encouraging practitioners 
towards new and more potent metaphors they describe an empowering and energising experience.

And finally, speaking of empowerment, conducting this overview of the journal's contents has reminded me again how this community began - from a sense of being disempowered, isolated and unheard. We came together to share ideas about a practice that seemed not to have been described or theorised previously. We offered support to each other and found value, first in establishing a network for discussion, next by holding conferences, and then by setting up the Association for Learning Development in Higher Education, ALDinHE. This latest initiative - a peer-reviewed academic journal - represents another step on our developmental journey. It follows closely on the heels of a conference in December 2008 organised jointly by ALDinHE and the Staff and Educational Development Association, SEDA, demonstrating that we hear Chris Rust's call to unite with our ED and other colleagues. Most of all it demonstrates our commitment to forge a stronger identity and voice for those who work directly with students in attempting to make sense of, and to make the best of, the experiences (and particularly the learning experiences) of higher education.

I hope you will find the journal stimulating and informative. It is a relatively modest collection of papers but represents a great deal of hard work on behalf of the contributors, the reviewers and editors. Do let us know your reactions and please tell others to read it. Most of all, please consider writing for our next edition. This will be published as soon as sufficient material has been accepted. Details of how to contribute can be found at http://www.aldinhe.ac.uk/ojs/. In closing, I would like to thank all who helped, but most especially my co-editor Andy Hagyard of the University of Lincoln. Andy's tireless and relentlessly cheerful efforts underpin every aspect of this publication and it is no exaggeration to say that without him this edition of the journal would not exist. 